\title{
PROFIT SHARING, SEPARATION AND TRAINING
}

\author{
Colin P. Green \\ Department of Economics, Lancaster University \\ Lancaster LA1 4YT, UK \\ John S. Heywood \\ Department of Economics, University of Wisconsin-Milwaukee and Birmingham Business \\ School, University of Birmingham
}

\begin{abstract}
Theory presents two channels through which profit sharing can increase worker training. First, it directly increases training by alleviating hold-up problems and/or encouraging co-workers to provide training. Second, it indirectly increases training by reducing worker separation and increasing training investment's amortization period. This paper provides the first attempt at separately identifying these two channels. We confirm a strong direct effect but also identify a weaker, more tenuous indirect effect. This suggests that profit sharing's influence on training is unlikely to operate primarily through its reduction on separations while simultaneously presenting the first evidence confirming the prediction of an indirect causation.
\end{abstract}

KEYWORDS: PROFIT SHARES, PERFORMANCE PAY, TRAINING, TURNOVER

JEL CODES: M52, M53, J63.

Corresponding Author: Colin P. Green

Lancaster University

c.p.green@lancaster.ac.uk

Phone: +44 (0) 1524594667

Fax: +44 (0)1524 59244 


\section{INTRODUCTION}

Profit sharing has been shown to be associated with higher firm profitability, labor productivity and worker wages (Bhargara 1994, Cable and Wilson 1989, Estrin et al. 1997, Hubler 1993, Kruse 1992, 1993, Wadhwani and Wall 1990). Yet, the recognized 1/N problem suggests that free riding dramatically limits the effectiveness of profit sharing as a direct incentive device to elicit greater effort and productivity. While particular technologies or forms of group behavior can help reduce the 1/N problem (Fitzroy and Kraft 1987; Adams 2006; Heywood and Jirjahn 2009), an alternative causation contends that profit sharing improves productivity by increasing investment in worker training. This paper estimates the influence of profit sharing on the provision of training.

There exist two strands from the literature suggesting how profit sharing spurs training. In the first, profit sharing plays an indirect role by reducing separation (Azfar and Danninger 2001; Gielen 2007). This reduced separation increases the expected amortization period for training investments and this, in turn, increases the likelihood of training. In the second, profit sharing plays a direct role either by creating a contract that rewards training thereby reducing fears of a hold-up problem and/or by encouraging co-workers to provide training (Itoh 1991, Parent 2004). We are the first to estimate the relationship between training and profit sharing in a framework that allows for both of these roles.

We mimic earlier work showing that the probability of separation is lower in the presence of profit sharing and that profit sharing stands as an important determinant of both receiving training and of its intensity. Critically, we extend these estimates to explicitly distinguish the direct and indirect effects. A series of recursive bivariate probits present a mixed pattern. For each of the measures designed to capture training, we confirm a direct effect but find evidence of 
an indirect effect through separation only when examining separation within a short period and only for certain types of training. While the joint estimation routinely confirms the role of profit sharing in reducing separation rates, those reduced rates often have little or no influence on training. These results suggest that profit sharing may increase investments in training by eliminating either hold up problems or lowering the cost of coworker provision but provide only modest support for the role played by reduced separation.

The next section highlights the hypothesis that profit sharing increases training but emphasizes the critical need for a new testing strategy. The third section reviews our data and the methods used. The fourth section presents the evidence on the association between profit sharing and job separation and between profit sharing and training. The fifth section summarizes our estimates that allow for both direct effects of profit sharing and indirect effects through reduced separation. A final section concludes.

\section{PROFIT SHARING AND TRAINING}

While the link between productivity and profit sharing may have several sources, one important suggestion is that profit sharing increases training. ${ }^{1}$ This importance grows when recognizing that the usual "incentive for effort" argument is undermined by the well-recognized $1 / \mathrm{N}$ problem. Parent (2004) presents convincing evidence that workers who received profit sharing on a previous job earn higher wages on their current job even in the absence of profit sharing on the current job. This he claims is unlikely in a model of eliciting effort but fits with the alternative conjecture that profit sharing is associated with greater investment in skills, including skills transferable between employers.

\footnotetext{
${ }^{1}$ Additional possibilities include that profit sharing reduces absence. See Wilson and Peel (1991), Brown et al. (1999), Chelius and Smith (1990) and Heywood and Jirjahn (2004).
} 
There exist two broad variations in the literature as to why profit sharing may increase training and so influence worker productivity. The first emphasizes the importance of profit sharing on separations and we label this a model of indirect causation as it suggests that the reduced separations are ultimately responsible for the greater incidence of training and so the higher productivity. The second variation is largely unrelated to separation and we label it a model of direct causation. Previous literature has not distinguished empirically between the direct and indirect models.

Profit sharing may reduce employee separations encouraging investment in firm specific capital as the expected amortization period for such investments grows. Kruse (1992) argues that workers may reduce their initiated separations because profit sharing "leads to greater identification with the firm," because workers may value the stronger link between compensation and effort implied by profit sharing and because when times are good and most favorable for employee job search, compensation naturally increases with profit sharing. At the same time, firms may reduce their initiated separations because profit sharing reduces the marginal cost of labor during periods of weak firm performance making redundancy less likely (Weitzman 1984). The existing evidence on the relationship between profit sharing and separation is somewhat mixed. D'Art and Turner (2004) fail to find any influence of profit sharing on separation in their large survey of firms in 11 European countries. Chelius and Smith (1990) found only "borderline" evidence in earlier US data claiming it was at best "suggestive." These studies contrast with the more recent US individual level estimations of Azfar and Danninger (2001) showing a strong negative influence of profit sharing on the probability of a worker being made 
redundant and also showing a negative influence of profit sharing on the probability of a worker quitting. $^{2}$

Azfar and Danninger (2001) combine their evidence that profit sharing reduces separations with similarly strong evidence that profit sharing is associated with increased training. They show that workers with profit sharing were 25 percent more like to receive training and that when trained, they received significantly more training as well. They argue that the combined findings that profit sharing reduces separations and that it increases training "support our hypothesis that greater job stability increases investment in firm-specific training" (Azfar and Danninger 2001, p. 626). Gielen (2007) uses UK data in a roughly similar fashion confirming in a single equation estimate that profit sharing increases the likelihood of training and in a separate estimate that both training and profit sharing reduce the likelihood of separation.

While recognizing the importance findings, the argument for indirect causation between profit sharing and training relies upon the reduced separation probability increasing the likelihood of training. Although longer expected tenure is taken as a basic theoretical determinant of training (Lynch 1991, 1993), the influence of reduced separation probabilities on training may not be large if firm specific training is actually rare, as indicated by Lowenstein and Spletzer (1999), and if most periods of unemployment following separation are short or non-existent. Thus, Royalty (1996) estimates the influence of predicted separation probabilities on the incidence of employerprovided training. She finds that the probability of "job to job" separation (the majority of separations for men) has no influence on training and that only the probability of "job to nonemployment" separation has a negative influence. This confirms the importance of expected

\footnotetext{
${ }^{2}$ Arranz-Aprete (2005) uses individual data from Finland confirming the negative influence of profit sharing on seperation. Earlier work by Kraft (1991) confirms that profit sharing decreases the number of dismissals while Kruse (1991) used more aggregate data showing that profit sharing firms had smaller employment decreases during economic downturns.
} 
employment duration not expected tenure duration. Veum (1997) finds a positive association between training off-the-job and worker separation and, at best, a weak negative association between employer-provided training and separation. Levine (1993) finds no evidence that across plants lower separation rates are associated with greater training. Using UK data Green et al (2000) find no relationship between training and mobility, while Elias (1994) finds no statistically significant link between male separation and the receipt of employer provided formal training. In short, researchers interested in the influence of profit sharing on training should not take for granted that a reduced probability of separation necessarily increases training. Moreover, even an observed correlation is not evidence of causation as training with employer specific aspects may cause longer tenure as separation causes lost returns.

Instead of an indirect influence through separation, there may be a direct link between profit sharing and training. Two channels have been suggested in the literature explaining how profit sharing may directly increase training. First, profit sharing has been seen as an explicit contract that helps alleviate the well-known "hold-up problem" associated with investments in firm specific training (FitzRoy and Kraft 1987). Firm specific skills are inherently difficult to contract upon and because they have no market value firms cannot be trusted to share the rents over those skills without resort to strong reputation effects. Moreover, even for general training, workers may fear a hold-up problem from their current employer if it is costly or time consuming to find alternative employment. Thus, "by writing a contract in which it is specified that workers get a certain percentage of profits, workers can feel more confident that they will not be held up ex post (Parent 2004: 38)." This may lead workers under profit sharing arrangements to devote more time investing in skills. Interestingly, this function might well be played by alternative performance pay schemes that allow workers to capture returns on their investment in training 
and improved performance (Kraft 1991). As a result, we will examine the role of both profit sharing and individual performance pay throughout our analysis. In either case, it is the explicit contract that rewards increased productivity that causes the investment not an indirect influence through a decreased risk of separation.

Second, profit sharing has been seen as directly encouraging "helping effort" in which workers allocate effort not only to their own tasks but also to assisting with the tasks of coworkers (Itoh 1991). Profit sharing thus helps reduce the confirmed tendency under individual incentives of ignoring the profitable allocation of effort to helping coworkers (Drago and Garvey 1996). Critically, training has very large elements of helping effort. Co-workers provide a large share of both formal and informal on-the-job training and do so by taking time away from other duties (Barron et al. 1989). The time and effort workers spend training co-workers has been thought to depend on the incentives they face. Profit sharing reduces the tendency to underprovide training effort. Indeed, Morrison and Wilhelm (2004) emphasize the role played by coworker training in professional service firms (such law firms) arguing that partnership arrangements in which the trained workers retain a share of profit are critical to ensuring that the appropriate degree of training is provided to new hires. Similarly, Encinosa et al. (2007) find that U.S. doctors receiving a share of firm profits rather than receiving earnings based on their individual contributions are more likely to consult with one another about cases and provide their expertise to colleagues. In this view profit sharing increases the incentive for informal and onthe-job training by co-workers and supervisors who might otherwise emphasize their own tasks. In this case, individual performance pay should work in the opposite direction as profit sharing. Explicit rewards for workers' own productivity should be at odds with helping and training newer 
hires as the diverted time increases overall productivity but not in ways rewarded by an individual based scheme.

\section{DATA AND APPROACH}

We use two longitudinal data sets from the UK that sample similar populations within similar time frames, the British Household Panel Survey (BHPS) and the 5 quarter longitudinal version of the UK Labour Force Survey (LFS). The BHPS is an annual longitudinal survey from 1991 to 2004. The longitudinal version of the LFS we use has been running since 1992 and comprises a five quarter rolling panel where each quarter a new cohort is observed. For both data sets, we limit our sample to male employees aged 20-65 who were not employed in the public sector.

We use these two data sets as each has off-setting strengths with respect to payment method information. The chief advantage of the LFS is its detailed measures of payment methods. From 1999 onwards, individuals record separately if they received tips, piece rates, bonuses, profit shares and a variety of compensatory wages (locality allowances, shift allowances etc). ${ }^{3}$ However, payment information is only available in the LFS for the first and last quarter that the individual is observed. Hence, for our purposes, it has only a limited panel dimension. The information on payment schemes in the BHPS is available for 1998 onwards and the questions asked are, "In the last 12 months have you received any bonuses such as a Christmas or quarterly bonus, profit-related pay or profit sharing bonus, or an occasional commission?", this excludes overtime payments; and "Does your pay include performance related pay" (Taylor et al, 2006). Hence the categorization of profit share receipt in the BHPS is broad. A key difference between the two data sets is the time domain that the payment method questions cover. For the BHPS,

\footnotetext{
${ }^{3}$ We group tips and piece rates into one category (performance pay).
} 
these relate to payments made in the last year. Due to the quarterly nature of the LFS, payment method information is effectively for the previous 13 weeks.

Both data sets allow the disaggregation of job separations into a number of categories, including quits, fires and redundancies. We observe job separations in the year following the observation of pay type. For the BHPS we have a panel of separations of up to 8 years, whereas with the structure of the LFS we effectively only observe one year of separation data on each individual.

Training information is quite detailed in the BHPS, and has been extensively used by researchers in the past (see for instance Arulampalam and Booth (1998) and Booth and Bryan (2006)). We focus on the incidence of employer funded training, general training and specific training. The LFS contains less detailed information on training, and much of this is only available for certain subsets of the data. However, unlike the BHPS, it has an explicit question on the incidence of informal on-the-job training. We use this to examine the role of profit shares on helping effort.

Table 1 provides summary statistics for the two data sets. In the BHPS roughly 42 percent of our sample report receiving a "profit share or bonus" in the past year and 19 percent report some form of performance pay. The more detailed pay scheme rates in the LFS appear somewhat lower; however recall that these are reported rates of payment in the past quarter. If these rates are roughly annualized, then profit share/bonuses are received by approximately 39 percent of male non-public sector employees. Whether the receipt of performance related pay is of a comparable level is dependant on how respondents in the BHPS viewed payments classified as compensatory wages and the other additional payments listed in the LFS. Otherwise the two 
samples appear roughly comparable, although there are slight variations by age and hours worked. Log weekly pay rates are noticeably lower in the LFS.

\subsection{EMPIRICAL APPROACH}

Our basic approach starts from past work by focusing on job separation over a future period (we test several alternative period lengths). The probability of a separation is a function of receiving profit sharing in the current period. Training is measured in the current period and also dependent on receiving profit sharing in the current period. We begin by reproducing findings for the UK similar to those of Azfar and Danninger (2001) for the US. Yet, we explicitly test for the indirect effect that they and Gielen (2007) only assume. Ultimately, future separation is estimated as a function of current profit sharing and, simultaneously, training is estimated as a function of both current profit sharing and future separation.

The recursive bivariate probit appropriate for this latter test belongs to the general class of multiple equation models with both continuous and discrete endogenous variables introduced by Heckman (1978). Following from this literature there exists a reduced form equation for separation as the potentially endogenous dummy and second structural form equation estimating the determinants of training:

$$
\begin{aligned}
& y_{1 i}^{*}=B_{1}^{\prime} x_{1 i}+\mu_{1 i} \\
& y_{2 i}^{*}=B_{2}^{\prime} x_{2 i}+\mu_{s i}=\delta_{1} y_{1 i}+\delta_{2}^{\prime} z_{2 i}+\mu_{2 i}
\end{aligned}
$$

where $y_{1 i}^{*}$ and $y_{2 i}^{*}$ are latent variables for separation and training provision with $y_{1 i}$ and $y_{2 i}$ dichotomous variables observed according to the rule: 


$$
y_{j i}=0 \text { if } y_{j i}^{*}>0 \text { and } y_{j i}=1 \text { if } y_{j i}^{*} \leq 0 \text { for } \mathrm{j}=1,2
$$

Here $x_{1 i}$ and $z_{2 i}$ are vectors of exogenous variables and the error terms $\left(\mu_{1 i}, \mu_{2 i}\right)$ are distributed bivariate normal with correlation coefficient $\rho$. Estimates of, and inference on, the parameters $\left(B_{1}^{\prime}, \delta_{1}, \delta_{2}^{\prime}, \rho\right)$ follow from the maximum likelihood method and the relevant log-likelihood (Maddala, 1983: 123). The likelihood ratio test (LR) provides the most suitable test for the exogeneity of $y_{1 i}$ (Monfardini and Radice 2008):

$$
H_{o}: \rho=0 \text { vs. } H_{a}: \rho \neq 0
$$

Under the null hypothesis the log-likelihood of the model becomes the sum of the log-likelihood functions of the two univariate probits estimated separately. Under the alternative hypothesis, simultaneous estimation is required and the resulting log-likelihood is compared to the sum under the null to conduct the test.

Despite the recursive structure, Wilde (2000) shows that identification can often be achieved by the non-linearity even if the exogenous variables are identical in both equations. Nonetheless, Monfardini and Radice (2008) show that adding a suitable instrument to the first equation remains critical in applied work as it preserves the validity of the LR exogeneity test when the distribution of errors is non-normal as can often be expected. As a consequence, we follow the instrumental variable estimation of (1). We discuss the instrument when we introduce our estimates in section 5 .

Recognize that profit sharing is a critical element of both $x_{1 i}$ and $z_{2 i}$. Direct causation would be supported by a significant coefficient on profit sharing in $\delta_{2}^{\prime}$ after correctly accounting for any potential endogeneity of the separation probability. Indirect causation would be supported 
by a significant coefficient on profit sharing in $B_{1}^{\prime}$ combined with a significant $\delta_{1}$ coefficient again after accounting for any potential endogeneity. Thus, the evidence in favor of the indirect causation that has been suggested in the literature depends critically on the multiple equation estimation that we are the first to undertake.

\section{PRELIMINARY EVIDENCE: PROFIT SHARING, TRAINING AND SEPARATION}

Probit estimates of the risk of job separation are reported in Table 2 for the BHPS and LFS, respectively. For ease of interpretation we report marginal effects. We present overall estimates of separation and have also estimated models disaggregated by quits, fires and redundancies (a subset of fires). Initially, risk of separation is estimated with standard errors clustered at the individual level. Both data sets present clear evidence that the receipt of profit sharing is associated with a lower risk of separation. ${ }^{4}$ Such systematic effects are not observed for other performance pay types.

\section{INSERT TABLE 2}

Table 3 provides preliminary evidence on the relationship between profit shares and training. It reports probit estimates of the impact of profit sharing on training incidence with standard errors clustered at the individual level. The estimates are reported for overall training incidence, along with the incidence of employer funded training, general training and specific training. ${ }^{5}$ Such a detailed level of disaggregation is not possible in the LFS. Instead, for the LFS we report estimates of the influence of payment method on overall training incidence and on the

\footnotetext{
${ }^{4}$ Furthermore, in unreported results we find that profit sharing is associated with both lower incidence of employee initiated separations (quits) and employer initiated separations (fires).

${ }^{5}$ In unreported estimates, the effect of profit shares on training intensity (days of training) largely follow the patterns of sign and significance reported in table 4 . These estimates are available from the authors.
} 
incidence of on-the-job training. All control variables are as reported in table 2, but for brevity only the estimated payment method effects are reported.

These estimates demonstrate that the receipt of profit sharing stands as a positive determinant of the incidence of training. The estimates for the disaggregated training incidence models also suggest a positive association between profit share receipt and the receipt of employer-funded training, specific training and general training. The magnitudes of these effects are roughly similar. Furthermore, evidence from the LFS indicates that profit sharing is positively associated with a higher incidence of informal on-the-job training, an effect that is not evident for performance pay. When combined with our inability to find a role for reduced separation probability on training (see section 5), this finding is consistent with the notion that profit sharing increases helping effort and so directly increases training within the workplace.

\section{INSERT TABLE 4}

It has been suggested that any observed relationship between profit shares and job separation may simply reflect the sorting of individuals by unobservable characteristics. Thus Kruse (1991) has suggested that profit sharing may be associated with firms and workers who value employment stability. As one illustration, workers who form strong bonds with co-workers may both sort into workplaces using profit sharing and be less likely to quit (Heywood et al. 2005). To investigate this and related possibilities, we re-estimate the models of overall separations for the BHPS where we utilize a fixed effects logit estimator in an attempt to control for unobserved individual level heterogeneity. ${ }^{6}$ The results from this model are reported in

\footnotetext{
${ }^{6}$ Two related problems emerge because the fixed effects logit estimator excludes observations with no variation in the dependent variable. First, the smaller sample size makes it difficult to gain efficient fixed effects estimates for the separation sub-categories. Second, the resulting sample may not be fully representative. We note that alternative fixed effects linear probability models yield profit share effects very similar in magnitude and significance to those
} 
column 1 of table 4 . This demonstrates that the sign and significance of profit sharing effects on separations are robust to the inclusion of individual level fixed effects.

Again, the estimated association between training and profit shares may merely signal that individuals who have higher unobservable propensity to train may sort into workplaces with profit sharing arrangements. We investigate this by again controlling for individual specific unobservable characteristics by re-estimating the model of overall training incidence via fixed effects logit. ${ }^{7}$ These estimates are reported in the remaining columns of table 4 . These retain the same signs and general significance as those reported in table 3, although the effect of profit sharing on overall training incidence just misses significance at the 10 per cent level.

\section{SEPARATING DIRECT AND INDIRECT EFFECTS}

The estimates above, as in previous studies, demonstrate a relationship between profit sharing and training, along with an association between profit sharing and separation. In this section we seek to provide evidence on the relative importance of the two channels suggested in the literature: the indirect relationship that works through the channel of profit sharing reducing separation and so making a larger share of training investments profitable and a direct effect of alleviating the hold-up problem in training and/or increasing the willingness of coworkers to provide training.

Our primary method is to estimate the recursive bivariate probit model described in Section 3. The essence of this estimation is that profit sharing enters as a determinant of separation risk and that both separation risk and profit sharing enter as determinants of receiving

reported in table 3. These estimates, and fixed effects logit estimates for the separation sub-categories, are available from the authors upon request.

${ }^{7}$ Again this strategy may introduce sample selection bias into our estimates. We re-estimated all the models reported in table 6 by linear probability model with fixed effects. This produced similar estimates of the effect of profit sharing/bonuses and performance pay on the incidence of training. 
training. As described, for such estimates to be robust, the reduced form estimate of separation risk should include an instrument that influences separation risk but is not a determinant of training.

Our identification strategy exploits a long recognized association between cigarette smoking and risk preference. Thus, Hersch and Viscusi (1990) and Hersch and Pickton (1995) use cigarette smoking to identify individuals with greater risk preference. Experiments on risk aversion confirm that those who undertake larger risks in the laboratory are significantly more likely to smoke (Barsky et al 1997). Moreover, cigarette smoking has been correlated with important labor market choices. Viscusi and Hersch (2001) demonstrate that US workers who smoke take substantially more risky jobs (in terms of injuries on the jobs). In the UK Brown et al. (2006) show that smokers are more likely to accept jobs with greater earnings and employment risk. The critical point from this literature is that smokers can be expected to receive less disutility from a given risk of job separation. As a consequence, in a hedonic labor market, we anticipate that workers that smoke will sort into jobs with higher expected separation risks.

At the same time that identification requires a variable that strongly determines a workers separation risk, that same variable should not influence the incidence of training itself. While some forms of training may be more risky than others, there is nothing about the association between smoking and risk that we think should influence the decision whether or not to undertake training itself. Alternatively, it might be argued that cigarette smokers will avoid training because of higher discount rates but the average length of training is sufficiently short that this is unlikely to be a crucial factor. Statistically, how many cigarettes an individual smokes per day appears unrelated to any of the measures of training incidence (an average absolute value T-Stat of 0.638) but it emerges as a strong determinant of separation risk. Moreover, a linear 
version of the model yields test statistics that are above the critical values outlined by Stock and Yogo $(2005)$ to detect weak instruments $(\mathrm{F}-\mathrm{Test}=10.571)$.

\section{INSERT TABLE 6}

Estimates of the recursive bivariate models of separation and training are reported in Table 6. These estimates use separation in the next year and show that the number of cigarettes is a strong positive determinant of the likelihood of separation. Yet, the addition of this variable does not change the important role that profit sharing plays as a direct negative determinant of the probability of job separation. The indirect effect would receive support if separation now influences training. It takes a routinely negative coefficient and that it emerges as significant in both the overall training and the general training estimates. This tends to support the notion in the literature that it is the ability of profit sharing to reduce separations that changes amortization periods and increases the profitability of training. Nonetheless, we emphasize that the direct effect of profit sharing remains. In three of the four specifications, profit sharing takes a positive and significant coefficient in the direct estimation even given the recursive structure. Moreover, in the insignificant specific training estimate, the summary specification statistics indicate that there is no gain to the recursive structure suggesting the positive coefficient on profit sharing from the single equation specification may be most appropriate.

The results present an important contrast from the single equation estimates we present and that have been presented in the literature. Profit sharing remains a negative determinant of separation and profit sharing remains a positive determinant of training. Yet, the jointly estimated results present the first support specifically in favor of the indirect causation that has been highlighted by previous researchers. Nonetheless, the results remain highly supportive of a direct effect such as reducing hold-up problems or encouraging co-worker provision. Certainly 
the fact that other types of performance pay are associated with greater training even as they have no influence on separation hints of the potential importance of the hold-up problem.

\subsection{ROBUSTNESS CHECKS}

It might be argued that estimating the impact of separation in the year following training is arbitrary. Indeed, it might be argued that if the period of amortization is the issue, the time frame should be longer. We estimated models using separation within the next 2 years and show the results in Table 6. Much of the pattern remains. First, the instrument continues to play a important role and pass the usual tests to reject weakness. Second, profit sharing continues to reduce the likelihood of separation. Third, profit sharing continues to be a strong and statistically significant direct determinant of training. Indeed, this is confirmed in all four estimates. Fourth, despite these similarities there is no longer confirmation of any indirect influence of profit sharing. While profit sharing reduces separation, the role of separation on training is routinely very far from statistical significance. Thus, our evidence of an indirect effect appears highly sensitive to both the measure of training (general vs. specific) and the use of one year period in which to measure separation. Extending the time period to separation over the next 3 years yields a pattern virtually identical to that in Table 6 with no support for the indirect effect.

It might be thought that our estimation is missing the critical role played by separation because of the range of tenures in our sample. Specifically, most separations may happen early in a workers' tenure and it is also at this time that most training is undertaken (Greenhalgh and Marvotas 1996). Thus, our estimations might fail to uncover the true negative influence of the separation probability on training that happens throughout most of a worker's later tenure. In unreported tests we re-estimated our models in Table 5 eliminating all workers within their first 
two years of tenure. While the point estimates move modestly, the direct effect of profit sharing remains strongly confirmed and there is no significant role for the estimated separation probability.

Separation may represent too coarse a separation variable. Instead risk of employer initiated separations (fires) may be more likely to effect employers' decisions on who to train (especially in firm specific skills). We re-estimated the models in Table 5 using fires instead of separations, again the point estimates of profit shares on training remain essentially unchanged. Third, it might be asked how the recursive IV performs on the LFS data with its somewhat different definitions of the critical variables. While there is no evidence on smoking, we estimated an analogous specification using homeownership as an IV determinant of separation. Despite the statistical success of the IV in determining separation but not training, there was evidence only of a direct effect for profit sharing.

Our results could be biased if profit sharing jobs are better quality job matches in some unobserved dimension. In this case profit share merely flags jobs that are likely to have lower separation and higher training for other reasons. Profit sharing could then be endogenous and the bias not removed by simple fixed effects. As a test of this possibility, we estimated a trivariate version of the models presented in Table 5. The additional equation is a profit sharing incidence model (probit) where the regressors are those from Table 2 (excluding profit sharing of course). We instrument this equation using year dummies which are subsequently omitted from the training and separation equations. While not strongly based on theory, these pass key instrument validity tests of overidentification and exclusion validity. This trivariate estimation does not materially affect the sign and significance of the profit sharing coefficients estimated in either the 
separation and training equations. This provides some reassurance that the observed effects of profit sharing reflect more than variations in unobserved job match quality.

\section{CONCLUSION}

This paper investigated one particular channel by which profit sharing may influence productivity, the effect of profit sharing on worker training. In particular, we distinguish between the direct effect of profit sharing on training through creating a contract that rewards training and/or encouraging co-workers to provide training, and the indirect effect through reduced separations and hence longer expected amortization period.

As a first step we use UK data to demonstrate that profit sharing is associated with lower separation rates and with greater provision of worker training. This is true of overall training incidence and intensity and also for sub-categories of training such as employer-funded, specific and general training. These results are robust to the inclusion of controls for individual fixed effects, simultaneity of training and separation, and remain once we attempt to control for the effect that profit sharing has on reducing the likelihood of future separation from the firm.

More generally, these direct effects on training are also present for other performance related pay. However, unlike performance related pay schemes that directly reward individual productivity, profit sharing may also increase informal and on-the-job training provision by coworkers. We present evidence that profit sharing does indeed increase the provision of informal on the job training, and that no such effect is present for other performance related pay.

Our attempts to identify an indirect effect of profit sharing reveal a mixed pattern. In two of the four types of training we can identify a significant indirect effect. Profit sharing emerges as a negative determinant of separation and lower separation is associated with an increased 
likelihood of training. This indirect influence did not prove robust to changes in the period over which separation was calculated or to several other alterations in specification. As a consequence, we suggest that the influence of profit sharing on training is unlikely to operate primarily through its reduction on separations while simultaneously presenting the first, if only suggestive, evidence supporting the theoretical prediction of an indirect causation 
TABLE 1 Summary Statistics, Male Non-Public Sector Employees Aged 20-65

\begin{tabular}{|c|c|c|c|c|}
\hline \multirow[b]{2}{*}{ Variables } & \multicolumn{2}{|c|}{ BHPS 1998-2004 } & \multicolumn{2}{|c|}{ LFS 1999-2004 } \\
\hline & Mean & Std Dev & Mean & Std Dev \\
\hline Profit Sharing/Bonuses & 0.426 & & & \\
\hline Performance Pay & 0.188 & & & \\
\hline Piece Rate/Tips & & & 0.008 & \\
\hline Profit Shares & & & 0.015 & \\
\hline Bonuses & & & 0.083 & \\
\hline Compensatory Wages & & & 0.075 & \\
\hline Other Additional Payments & & & 0.039 & \\
\hline Age (years) & 37.921 & 11.134 & 40.450 & 11.952 \\
\hline Tenure (years) & 11.540 & 7.433 & & \\
\hline \multicolumn{5}{|l|}{ Tenure: $0-3$ months } \\
\hline 3-6 months & & & 0.110 & \\
\hline 6-12 months & & & 0.219 & \\
\hline $1-2 \mathrm{yrs}$ & & & 0.161 & \\
\hline $2-5 \mathrm{yrs}$ & & & 0.219 & \\
\hline $5-10 \mathrm{yrs}$ & & & 0.161 & \\
\hline $10 \mathrm{yrs}+$ & & & 0.341 & \\
\hline Married & 0.581 & & 0.640 & \\
\hline \multicolumn{5}{|l|}{ Highest Level of Education: } \\
\hline$<$ A-Level & 0.526 & & 0.511 & \\
\hline A-Level & 0.237 & & 0.272 & \\
\hline Diploma/Vocational* & 0.089 & & 0.096 & \\
\hline Degree & 0.119 & & 0.143 & \\
\hline Higher Degree & 0.029 & & - & \\
\hline Log Pay (£1996) & 6.482 & 1.026 & 5.506 & 0.636 \\
\hline Normal Hours Worked & 40.040 & 6.923 & 42.980 & 12.354 \\
\hline Union Member & 0.219 & & 0.259 & \\
\hline Temporary Job & 0.032 & & 0.038 & \\
\hline \multicolumn{5}{|l|}{ Firm Size: 1-24 workers } \\
\hline 25-99 workers & 0.256 & & & \\
\hline 100-499 workers & 0.267 & & & \\
\hline 500 workers plus & 0.161 & & & \\
\hline Observations & 14047 & & 40269 & \\
\hline
\end{tabular}

Source: BHPS, LFS 
TABLE 2 Estimates of the Probability of Separation (Marginal Effects), Male Non-Public Sector Employees Aged 20-65.

\begin{tabular}{|c|c|c|}
\hline & BHPS 1998-2004 & LFS 1999-2004 \\
\hline Profit Share & $-0.041 *[0.007]$ & $-0.028 * *[0.013]$ \\
\hline Bonus & & $0.008[0.005]$ \\
\hline Performance Pay & $0.005[0.008]$ & $0.010[0.015]$ \\
\hline Compensatory Pay & & $-0.009[0.006]$ \\
\hline Other Bonus & & $0.008[0.005]$ \\
\hline Age & $0.001[0.002]$ & $0.001[0.001$ \\
\hline $\mathrm{Age}^{2}$ & $-0.0001[0.00002]$ & $-0.00003 *[0.00001]$ \\
\hline Tenure (days) & $-0.005^{*}[0.0004]$ & \\
\hline Tenure: $3-6$ months & & $-0.026 *[0.007]$ \\
\hline 6-12 months & & $-0.033 *[0.006]$ \\
\hline $1-2 \mathrm{yrs}$ & & $-0.047 *[0.006]$ \\
\hline $2-5 \mathrm{yrs}$ & & $-0.075 *[0.006]$ \\
\hline $5-10 \mathrm{yrs}$ & & $-0.102 *[0.006]$ \\
\hline $10 \mathrm{yrs}+$ & & $-0.139 *[0.006]$ \\
\hline Married & $-0.013[0.008]$ & $0.011 *[0.003]$ \\
\hline A-Level & $0.020 * *[0.009]$ & $0.006 * * *[0.004]$ \\
\hline Diploma & $0.030 * *[0.013]$ & $0.010 * *[0.005]$ \\
\hline Degree or Higher & $0.028 * *[0.011]$ & $-0.008 * * *[0.005]$ \\
\hline Log Weekly Wage & $-0.009 * *[0.004]$ & $-0.009 *[0.003]$ \\
\hline Normal Hours & $0.001 * *[0.0004]$ & $0.0004 *[0.0001]$ \\
\hline Union & $-0.051 *[0.009]$ & $-0.024 *[0.004]$ \\
\hline Temporary Worker & $0.165^{*}[0.017]$ & $0.050 *[0.006]$ \\
\hline Firm Size 50-99 & 0.010 [0.009] & \\
\hline Firm Size 100 to 500 & -0.013 [0.009] & \\
\hline Firm Size 500+ & $-0.001[0.001]$ & \\
\hline Constant & -0.132 & -0.095 \\
\hline Pseudo $r^{2}$ & 0.053 & 0.075 \\
\hline Observations & 14047 & 40269 \\
\hline
\end{tabular}

Source: BHPS, LFS. Standard errors clustered at the individual level in parentheses. *, ** indicate statistical significance at the $1 \%$ and $5 \%$ level, respectively. Controls included but not reported: year, industry, occupation and region controls. 
TABLE 3 The Effect of Payment Method on Training Incidence (Marginal Effects), Male NonPublic Sector Employees Aged 20-65.

\section{BHPS 1998-2004}

Trained? Employer Funded Specific Training General

Training Training

\begin{tabular}{lrrrr}
\hline Profit Share/Bonus & $0.038^{*}[0.008]$ & $0.036 *[0.007]$ & $0.041^{*}[0.008]$ & $0.037 *[0.008]$ \\
Performance Pay & $0.034 *[0.011]$ & $0.017 * *[0.008]$ & $0.031^{*}[0.010]$ & $0.032 *[0.011]$ \\
Observations & 14,047 & & &
\end{tabular}

LFS 1999-2004

Trained in the last On the Job Training 13 weeks?

in last 4 weeks?

\begin{tabular}{lcc}
\hline Profit Share & $0.092^{*}[0.019]$ & $0.044 *[0.013]$ \\
Bonus & $0.033^{*}[0.008]$ & $0.009[0.005]$ \\
Performance Pay & $-0.001[0.025]$ & $-0.007[0.014]$ \\
Compensatory Pay & $0.009[0.009]$ & $0.044 *[0.006]$ \\
Other Bonus & $0.053 *[0.012]$ & $0.002[0.007]$ \\
Observations & 40,269 & \\
\hline
\end{tabular}

Source: BHPS, LFS. Standard errors clustered at the individual level in parentheses. *, ** indicate statistical significance at the $1 \%$ and $5 \%$ level, respectively. Controls included but not reported: year, industry, occupation, and region controls along with all other controls included in table 2. "On the job training" means learning by example and practice while actually doing the job. Any training conducted in a classroom or training section, even if on the employers premises is not "on the job training". (ONS, 2005) 
TABLE 4 Fixed Effects Estimates of Seperation and Training (Average Effects), Male Non-Public Sector Employees Aged 20-65, BHPS.

\begin{tabular}{|c|c|c|c|c|c|}
\hline & Separation & Trained? & Employer Funded Training & Specific Training & General Training \\
\hline Profit Share/Bonus & $-0.151 * *[0.071]$ & $0.105[0.069]$ & $0.241 *[0.077]$ & $0.200 *[0.072]$ & $0.146 * *[0.071]$ \\
\hline Performance Pay & $-0.041[0.091]$ & $0.134[0.080]$ & $0.083[0.089]$ & $0.155 * *[0.082]$ & $0.153 * *[0.082]$ \\
\hline Observations & 6,049 & 7,043 & 5,633 & 6,501 & 6,692 \\
\hline
\end{tabular}


TABLE 5 Recursive Bivariate Probit Estimates of Profit Share Effects on Training and Separation, Male Non-Public Sector Employees Aged 20-65

\begin{tabular}{|c|c|c|c|c|}
\hline & Trained? & $\begin{array}{c}\text { Employer } \\
\text { Funded } \\
\text { Training }\end{array}$ & $\begin{array}{l}\text { Specific } \\
\text { Training }\end{array}$ & $\begin{array}{l}\text { General } \\
\text { Training }\end{array}$ \\
\hline \multirow[t]{2}{*}{ Profit Share/Bonus } & $0.077 * * *$ & $0.134 *$ & 0.083 & $0.083 * * *$ \\
\hline & {$[0.045]$} & {$[0.052]$} & {$[0.101]$} & {$[0.046]$} \\
\hline \multirow[t]{2}{*}{ Performance pay } & $0.124^{*}$ & $0.099 *$ & $0.125^{*}$ & $0.124 *$ \\
\hline & {$[0.033]$} & {$[0.035]$} & {$[0.040]$} & {$[0.033]$} \\
\hline \multirow[t]{3}{*}{ Separation } & $-0.912 * *$ & -0.515 & -1.088 & $-0.879 * *$ \\
\hline & {$[0.389]$} & {$[0.620]$} & {$[0.832]$} & {$[0.413]$} \\
\hline & \multicolumn{4}{|c|}{ Separation } \\
\hline \multirow[t]{2}{*}{ Profit Share/Bonus } & $-0.163 *$ & $-0.164 *$ & $-0.165^{*}$ & $-0.166^{*}$ \\
\hline & {$[0.027]$} & {$[0.027]$} & {$[0.027]$} & {$[0.028]$} \\
\hline \multirow[t]{2}{*}{ Performance pay } & 0.026 & 0.027 & 0.030 & 0.029 \\
\hline & {$[0.035]$} & {$[0.036]$} & {$[0.036]$} & {$[0.035]$} \\
\hline \multirow[t]{2}{*}{ No of Cigarettes } & $0.005^{*}$ & $0.005 * *$ & 0.004 & $0.005^{*}$ \\
\hline & {$[0.001]$} & [0.002] & {$[0.028]$} & {$[0.001]$} \\
\hline \multirow[t]{2}{*}{ Rho } & $0.578 * * *$ & 0.306 & 0.658 & $0.559 * * *$ \\
\hline & [0.243] & {$[0.370]$} & {$[0.562]$} & {$[0.258]$} \\
\hline $\begin{array}{l}\text { LR Exogeneity test } \\
\text { (chi-squared) }\end{array}$ & 3.243 & 0.600 & 0.632 & 2.815 \\
\hline Observations & 14047 & & & \\
\hline
\end{tabular}

Source: BHPS. Standard errors in parentheses. ***, *** indicate statistical significance at the $1 \%, 5 \%$ and $10 \%$ level, respectively. Controls included but not reported: year, industry, occupation, region controls along with all other controls included in table 2. 
TABLE 6 Recursive Bivariate Probit Estimates of Profit Share Effects on Training and Separation within the Next 2 Years, Male Non-Public Sector Employees Aged 20-65

\begin{tabular}{|c|c|c|c|c|}
\hline & Trained? & $\begin{array}{c}\text { Employer } \\
\text { Funded } \\
\text { Training }\end{array}$ & $\begin{array}{l}\text { Specific } \\
\text { Training }\end{array}$ & $\begin{array}{l}\text { General } \\
\text { Training }\end{array}$ \\
\hline \multirow[t]{2}{*}{ Profit Share/Bonus } & $0.130^{*}$ & $0.167 *$ & $0.163^{*}$ & $0.138^{*}$ \\
\hline & {$[0.044]$} & {$[0.033]$} & [0.039] & {$[0.037]$} \\
\hline \multirow[t]{2}{*}{ Performance pay } & $0.129^{*}$ & $0.089 * *$ & $0.129^{*}$ & $0.128 *$ \\
\hline & {$[0.035]$} & {$[0.036]$} & {$[0.036]$} & {$[0.035]$} \\
\hline \multirow[t]{3}{*}{ Separation } & -0.234 & 0.210 & -0.152 & -0.103 \\
\hline & {$[0.685]$} & {$[0.460]$} & [0.613] & {$[0.542]$} \\
\hline & \multicolumn{4}{|c|}{ Separation } \\
\hline \multirow[t]{2}{*}{ Profit Share/Bonus } & $-0.114 *$ & $-0.114 *$ & $-0.115^{*}$ & $-0.114^{*}$ \\
\hline & {$[0.030]$} & {$[0.030]$} & {$[0.030]$} & {$[0.030]$} \\
\hline \multirow[t]{2}{*}{ Performance pay } & 0.027 & 0.027 & 0.027 & 0.028 \\
\hline & {$[0.037]$} & {$[0.037]$} & {$[0.037]$} & {$[0.037]$} \\
\hline \multirow[t]{2}{*}{ No of Cigarettes } & $0.006^{*}$ & $0.006^{*}$ & $0.006^{*}$ & $0.006^{*}$ \\
\hline & {$[0.002]$} & {$[0.002]$} & {$[0.002]$} & {$[0.002]$} \\
\hline \multirow[t]{2}{*}{ Rho } & 0.167 & -0.120 & 0.086 & 0.086 \\
\hline & {$[0.413]$} & {$[0.271]$} & {$[0.125]$} & {$[0.326]$} \\
\hline $\begin{array}{l}\text { LR Exogeneity test } \\
\text { (chi-squared) }\end{array}$ & 0.157 & 0.192 & 0.053 & 0.070 \\
\hline Observations & 12955 & & & \\
\hline
\end{tabular}

Source: BHPS. Standard errors in parentheses. *** indicate statistical significance at the $1 \%$ and $5 \%$ level, respectively. Controls included but not reported: year, industry, occupation, region controls along with all other controls included in table 2. 


\section{REFERENCES}

Adams, Christopher P. 2006. "Optimal Team Incentives with CES Production." Economics Letters, Vol. 92, pp. 143-48.

Arranz-Aperte, Laura. 2005. "Profit Sharing and Employment Stability: Does Profit Sharing help You Keep Your Job?" Working Paper, Swedish School of Economics and Business Administration.

Arulampalam, Wiji. and Booth, Alison. 1998. "Training and Labour Market Flexibility: Is There a Trade-off." British Journal of Industrial Relations, Vol. 36, pp. 521-536.

Azfar, Omar and Danninger, Stephan. 2001. "Profit Sharing, Employment Stability and Wage Growth," Industrial and Labor Relations Review, Vol. 54, pp. 619-30.

Barron, John .M., Black, Daniel A. and Lowenstein, Mark.A. 1989. "Job Matching and On-theJob Training," Journal of Labor Economics, Vol. 7, pp. 1-19.

Barsky, Robert B., F. Thomas Juster, Miles S. Kimball and Mathew D. Shapiro. 1997. "Preference Parameters and Behavioral Heterogeneity: An Experimental Approach in the Health and Retirement Study." Quarterly Journal of Economics, Vol. 112, pp. 537-79.

Bassanini, Andrea, Allison Booth, Giorgio Brunello, Maria De Paola and Edwin Leuven. 2005. "Workplace Training in Europe." IZA Discussion Paper No. 1640.

Bhargara, Sandeep. 1994. "Profit Sharing and the Financial Performance of Companies: Evidence from UK Panel Data." Economic Journal, Vol. 104, pp. 1044-56.

Booth, Alison and Bryan, Mark. 2005. "Testing Some Predictions of Human Capital Theory: New Training Evidence from Britain." Review of Economics and Statistics, Vol. 87, pp. 391394. 
Brown, Sarah, Fakhfakh, Fathi. and Sessions, John G. 1999. "Absenteeism and Employee Sharing." Industrial and Labor Relations Review, Vol. 52, pp. 234-51.

Brown, Sarah, L. Farrell, Mark N. Harris and John G. Sessions. 2006. "Risk Preference and Employment Contract Type," Journal of the Royal Statistical Association A, Vol. 169, pp. 849-863.

Cable, John and Nicholas Wilson. 1989. "Profit Sharing and Productivity: An analysis of UK Engineering Firms." Economic Journal, Vol. 99, pp. 366-75.

Chelius, James and Robert S. Smith. 1990. "Profit Sharing and Employment Stability." Industrial and Labor Relations Review, Vol. 43, pp. 256-81.

D'Art, D. and T. Turner. 2004. "Profit Sharing, Firm Performance and Union Influence in Selected European Countries." Personnel Review, Vol. 33, pp. 335-350.

Drago, Robert and Gerald T. Garvey. 1996. "Incentives for Helping on the Job: Theory and Evidence." Journal of Labor Economics, Vol. 16, pp. 1-25

Elias, Peter. 1994. "Job-Related Training, Trade Union Membership, and Labour Mobility: A Longitudinal Study." Oxford Economic Papers, Vol. 46, pp. 563-578.

Encinosa, William E., Martin Gaynor and James B. Rebitzer. 2007. "The sociology of groups and the economics of incentives: Theory and evidence on compensation systems." Journal of Economic Behavior \& Organization, Vol. 62, pp. 187-214.

Estrin, Saul, Virginie Perotin, Andrew Robinson and Nicholas Wilson. 1997. "Profit-Sharing in OECD Countries: A Review and Some Evidence." Business Strategy Review, Vol. 8, pp. 27 32. 
FitzRoy, Felix and Kornelius Kraft. 1987. "Cooperation, Productivity and Profit Sharing." Quarterly Journal of Economics, Vol. 85, pp. 23-35.

Gielen, Anne C. 2007. "Performance Pay, Training and Labor Mobility," IZA Discussion Paper No. 2932.

Green, Francis, A. Felstead, Kenneth Mayhew and A. Pack 2000. "The Impact of Training on Labour Mobility: Individual and Firm-level Evidence from Britain." British Journal of Industrial Relations, Vol. 38, pp. 261-275.

Greenhalgh, Christine A. and G. Mavrotas. 1996. "Job Training, New Technology and Labour Turnover." British Journal of Industrial Relations, Vol. 34, pp. 131-50.

Heckman, James J. (1978) `Dummy Endogenous Variables in a Simultaneous Equation System’, Econometrica, vol 46, pp. 931-959.

Hersch, Joni and Pinkton, T.S. (1995). 'Risk Taking Activities and Heterogeneity of Job-Risk Tradeoffs'. Journal of Risk and Uncertainty, vol. 11, pp. 205-17.

Hersch, Joni and W. Kip Viscusci. 1990. "Cigarette Smoking, Seatbelt Use and Differences in Job-Risk Tradeoffs." Journal of Human Resources, Vol. 25, pp. 202-27.

Heywood, John S and Uwe Jirjahn. 2004. "Teams, Teamwork and Absence." Scandinavian Journal of Economics, Vol. 106, pp. 765-83.

Heywood, John S. and Uwe Jirjahn. 2006. "Performance Pay: Determinants and Consequences," in (D.Lewin ed), Contemporary Issues in Employment Relations, Champaign Illinois: Labor and Employment Relations Association.

Heywood, John S., Uwe Jirjahn and Georgi Tsertsvardze. 2005. "Getting along with Colleagues: Does Profit Sharing Help or Hurt?" Kyklos, Vol. 58, pp. 447-73. 
Hubler, Olaf. 1993. "Productivity, earnings, and profit sharing: An econometric analysis of alternative models." Empirical Economics, Vol. 18, pp. 357-80.

Itoh, Hideshi 1991. "Incentives to Help in Multi-agent Situations." Econometrica, Vol. 59, pp. 611-36.

Kraft, Kornelius. 1991. "The Incentive Effects of Dismissals, Efficiency Wages, Piece-Rates and Profit Sharing," Review of Economics and Statistics, Vol. 73, pp. 451-59.

Kruse, Douglas L. 1991. "Profit Sharing and Employment Variability: Microeconomic Evidence on the Weitzman Theory." Industrial and Labor Relations Review, Vol. 44, pp. 437-53.

Kruse, Douglas L. 1992. "Profit Sharing and Labor Productivity: Microeconomic Evidence from the United States." Economic Journal, Vol. 102, pp. 24-36.

Kruse, Douglas L. 1993. Profit Sharing: Does it Make A Difference, W.E. Upjohn Institute, Kalamazoo MI.

Levine, David. 1993. "Worth Waiting For? Delayed Compensation, Training, and Turnover in the United States and Japan." Journal of Labor Economics, Vol. 11, pp. 724-752.

Lowenstein, Mark A. and James R. Spletzer. 1999. "General and Specific Training: Evidence and Implications." Journal of Human Resources, Vol. 34, pp. 710-34.

Lynch, Lisa. 1991. "The Role of Off-the-Job vs. On-the-Job Training for the Mobility of Women Workers." American Economic Review, Vol. 81, pp. 151-56.

Lynch, Lisa. 1993. "The Economics of Youth Training in the United States." The Economic Journal, vol. 103, pp. 1292-1302. 
Maddala, G. (1983). Limited Dependent and Qualitative Variables in Econometrics, Cambridge University Press, New York.

Monfardini, Chara and Radice, Rosalba. 2008. "Testing Exogeneity in the Bivariate Probit Model: A Monte Carlo Study." Oxford Bulletin of Economics and Statistics, Vol. 70, pp. 271282.

Morrison, Alan D. and William J. Wilhelm. (2004). "Partnership Firms, Reputation, and Human Capital." American Economic Review, vol. 94, pp. 1682-1692.

Office of National Statistics (ONS). (2005). Labour Force Survey User Guide.

Parent, Daniel. 2004. "Incentives? The Effect of Profit Sharing Plans Offered by Previous Employers on Current Wages." Economics Letters, Vol. 83, pp. 37-42.

Royalty, Anne B. (1996). 'The Effects of Job Turnover on the Training of Men and Women,' Industrial and Labor Relations Review, vol. 49, pp. 506-21.

Stock, J. and Yogo, M. (2005). 'Testing for Weak Instruments in Linear IV Regression', NBER Technical Working Paper 284.

Taylor, M.F., Brice, J., Buck, N. and Prentice-Lane, E. (2006). British Household Panel Survey User Manual Volume B: Codebook. Colchester: University of Essex.

Veum, Jonathan R. 1997. "Training and Job Mobility Among Young Workers in the United States." Journal of Population Economics, Vol. 10, pp. 219 -33.

Viscusi, W. Kip and Joni Hersch. 2001. "Cigarette Smokers as Job Risk Takers." Review of Economics and Statistics, Vol. 83, pp. 269-280. 
Wadhwani, Sushil. and Martin Wall. 1990. "The Effects of Profit Sharing on Employment, Wages, Stock Returns and Productivity: Evidence from UK Micro-Data." Economic Journal, Vol. 100, pp. 1-17.

Weitzman, Martin. (1984), The Share Economy Cambridge MA: Harvard University Press.

Wilde, Joachim. 2000. "Identification of Multiple Equation Probit Models with Endogenous Dummy Regressors." Economics Letters, Vol. 69, pp. 309-312.

Wilson, Nicholas and Michael J. Peel. 1991. "The Impact on Absenteeism and Quits of Profit Sharing and Other Forms of Employee Participation." Industrial and Labor Relations Review Vol. 44, pp. $455-68$. 